\title{
PVC Plastic Tube with Concrete Infill Strengthened with FRP: A State-of- the-art Review
}

\author{
Nwzad Abduljabar Abdulla \\ Department of Civil Engineering, College of Engineering, Salahaddin Univ., Kirkuk Rd., Erbil, Republic of Iraq \\ E-mail: anwzad@yahoo.com
}

Received: 31 July 2020; Accepted: 31 August 2020; Available online: 5 October 2020

\begin{abstract}
The strength and energy absorption capacity of concrete compression members are a significant concern when considering the structural performance under axial and lateral loads. A lot of methods and different techniques have been proposed in the past to improve the behavior of concrete columns under the applied loads. One such technique is the concrete filled-plastic tube (CFPT) strengthened externally with fiber-reinforced polymers (FRP). Such a system can improve the durability of the structural members. A review of the research work on the durability of the new system under axial and flexural loads is presented. Moreover, a comparison and a brief discussion of the reported results are displayed.
\end{abstract}

Keywords: Plastic tube; CFPT; FRP; Strength; Durability.

\section{Introduction}

Durability and protection of existing infrastructures increased the demand for rehabilitating and retrofitting of concrete compression members found in building substructures and bridges. Durability and maintenance of infrastructure systems demand the allocation of significant resources. It is estimated a spent of 2 trillion US\$ on infrastructure construction and repairs in the Asian areas alone in the year 2000 [1]. Continuous increase in costly rehabilitation works can burden the development and economic growth of the society. Composite materials technology is a convenient alternative to conventional reinforcement in infrastructure construction and applications. In the past, several materials have been investigated to improve the performance of concrete, including steel ties [2] and spirals [3], steel tubes [4], (FRP) [5], polymeric polyvinyl chloride (PVC) tubes [6-19]. Such systems have been considered as useful for increasing strength of unconfined concrete and enhancing the durability. Over the last five decades, considerable attention focused on CFPT composite materials due to their many advantages [15].

However, these composite materials still cannot fulfill all the engineering requirements, and they lack the necessary stiffness required for structural applications [11]. Such a requirement could be fulfilled using FRP externally applied to increase the stiffness of the system [9]. Although FRP composites have been known for their effectiveness in enhancing strength and ductility, they still have not been widely adopted in the construction industry due to the high cost of materials and time-consuming repair techniques and lack of detailed design guidelines. Fiber-reinforced polymers consist of two components brittle fibers with high stiffness and strength, and a thermosetting polymer matrix with many inferior properties. Recently composite columns made of flexible PVC tubular and FRP wraps as an external shell with concrete core have attracted attention due to its many advantages. One advantage is to reduce the cost and improve the ductility of the CFPT-FRP composite system [20]. Use and potential applications of composite materials like plastic tube externally strengthened with FRP to confine cementitious composite materials like concrete are reviewed with more emphasis on the PVC tube component since the FRP component has been well documented. The durability of CFPT-FRP members used in civil and construction applications is reviewed. These include PVC jacket, CFPT-FRP members under compression, and flexure.

\section{Previous studies}

Concrete-filled tubes have been widely used in buildings and bridge piers. Lack of confinement is one of the shortcomings of concrete columns [21]. Toutanji and Saafi [20] has used a column consisting of a concrete-filled PVC tube externally reinforced with FRP strips at different spacing for new construction. In that system, the plastic tube acts as the formwork while the FRP provides additional confinement to the cast-in-place concrete core. The external surface of the plastic tube was grooved in the lateral direction to embed the fiber strips. Fig.1 shows 
three possible types of tube surface grooving; (a) the grooves are equally spaced in the lateral direction;(b) the grooves are inclined at an angle of 45 degrees, (c) the surface grooves are inclined at an angle of 135 degrees.
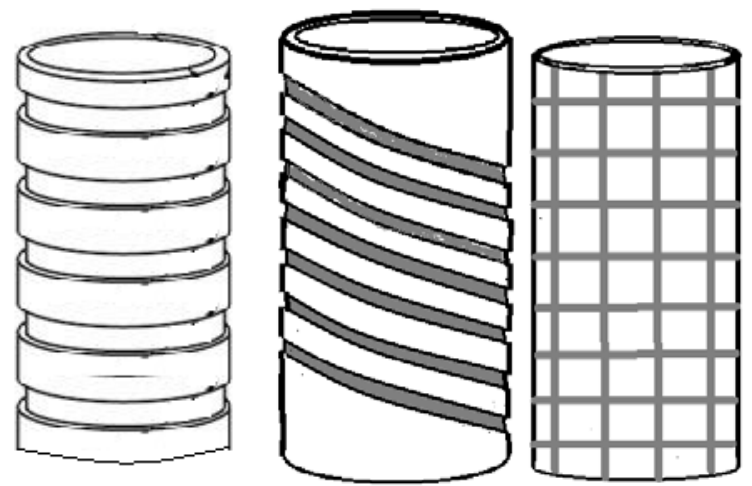

Fig. 1. Surface grooving of plastic tube: (a) surface grooves at angle $0^{\circ}$; (b) surface grooves at angle $45^{\circ}$; (c) surface grooves at orthogonal angle.

The effect of surface grooving on the plastic tube performance under load was simulated [22] using an ANSYS finite element package to model the compressive properties and crushing response of circular grooved PVC tubes subjected to static axial testing, Fig. 2. The system can be considered more economical than other FRP confining methods [20] since it consumes fewer fibers but with similar strength and toughness characteristics. The composite system exhibited high strength and ductility under axial load and a new design procedure for CFPT-FRP composite system was proposed to achieve more durable and economic structures.

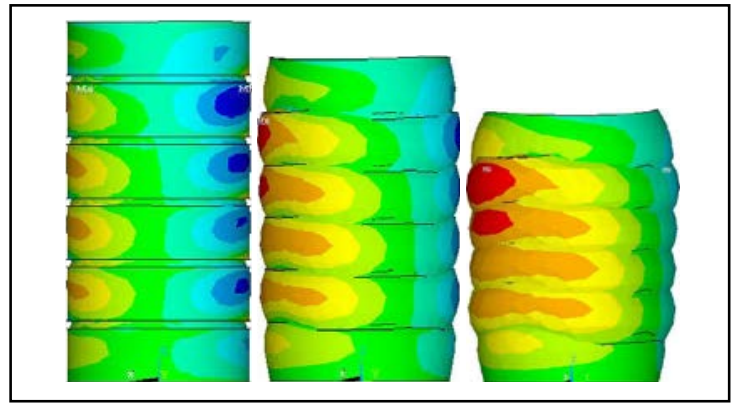

Fig.2. Modeling the modes of collapse observed in the series of static compression tests [22].

CFPT-FRP is a composite system in which the FRP shell acts as reinforcement in the axial and hoop directions. However, the compressive strength of PVC strengthened with FRP is the compressive strength of the PVC tube only. The PVC tube has enough stiffness to resist the initial crack and lateral deformation of concrete core and stress transfer from the FRP strips to concrete. At later stages of loading, the PVC tube transfer confining stresses uniformly from FRP strips to the concrete core and resist compressive stress from applied vertical load [23]. The axial capacity of PVC-FRP tube mainly related to the equivalent confinement effect coefficient and is expressed [23] by:

$$
\begin{aligned}
& N_{a}=A_{c} f_{c o}+\left(1+1.31 \xi_{e f}\right) \\
& \xi_{\text {ef }}=\frac{A_{f} f_{f}}{A_{c} f_{c o}} K_{g}
\end{aligned}
$$

where $A_{f}$ and $f_{f}$ are the cross-sectional area and the ultimate tensile strength of CFRP, $A_{c}$ and $f_{c o}$ are the crosssectional area and compressive strength of unconfined concrete and $K_{g}$ is the confining influence coefficient of CFRP strips.

$$
K_{g}=\frac{S_{f}}{S^{\prime}}
$$

where $S_{f}$ is the width of CFRP strips, $S^{\prime}$ is the hoop spacing of CFRP strips, and $S^{\prime} \geq S_{f}$. a bilinear model was developed [23] to predict the stress-strain of the CFPT-FRP column. Results show good agreement between 
numerical and experimental data. The engineering society and industry has shown considerable interest in seeking solutions and developing innovative and cost-effective techniques to mitigate the damage caused by seismic loads. Identifying new structural strengthening methods is a significant point of interest for structural and material engineers [17]. Fakharifar et al. [24] used plastic instead of steel tubes to confine concrete in the Concrete Filled Tube (CFT) system for the seismic design of reinforced concrete columns. The proposed CFT system yielded better results in terms of strength and ductility.

When FRP was introduced to the CFT system as an external shell, the composite action of CFPT-FRP produced a considerable enhancement in the strength of the composite columns. The authors reported that the efficacy of PVC tubular implemented in CFT columns was demonstrated under uniaxial compressive tests [24]. Jiang et al. [25] examined six concrete filed CFPT-FRP tubes under reversed loading. Failure modes, hysteretic characteristics, ductility, energy dissipation ability were studied to evaluate the seismic behavior of CFPT-FRP columns with carbon and basalt fibers. Test results revealed good hysteretic behavior, but when the outer CFPT-FRP tubes fractured or failed, the lateral bearing capacity dropped suddenly, before the failure of the columns. The performances of CFPT-FRP specimens with basalt fibers were inferior to those of CFPT-FRP with carbon fibers, evaluated in terms of lateral peak load, stiffness, and energy dissipation capacity.

PVC-concrete composite columns show a high energy absorption capacity. Test results reported by Jiang et al. [25] show the reinforced concrete column with designation B0, confined with a PVC tube only had a ductility factor of 5.74 compared with 6.02 for a similar column, B3-3, but confined with CFPT-FRP column having basalt fibers.

Fakharifar and Chen [26] introduced a new composite confinement system consisting of columns with FRP wraps, PVC tube, and with or without compressible Foam (as impact absorption medium) in between (CCFPT). The study program covered five concrete filled PVC (CFPT) tubes and fourteen FRP, carbon (C) or glass (G), wrapped concrete specimens (FW) having 305mm height, and 152mm diameter under axial compressive load. The influence of compressible Foam as an energy dissipation medium on the post-peak behavior of the CCFPT specimen was explored. The authors reported that when excluding the compressible Foam, the behavior of CCFPT specimens resembled the FW specimens in stress-strain relationships with brittle failures upon FRP rupture and immediately followed by PVC fracture due to sudden transfer in confining pressure. With compressible Foam included, the CCFPT specimens were able to combine the strength of the FW specimens and the ductility of the CFPT specimens. The authors reported that the nominal confinement ratio of a PVC tube could be calculated from:

$$
\left(\frac{f l u}{f c o}\right)_{P V C}=\frac{2 t_{P V C} f_{y P V C}}{D_{\text {int }} f_{c o}}
$$

where $2 t_{P V C}$ is thickness of tube; $f_{y P V C}$ is yield strength; $D_{\text {int }}=$ internal diameter of the PVC tube. Furthermore, the confinement pressure of PVC tube was approximately equivalent to half that of provided by 1 ply of CFRP or GFRP.

\section{CFPT-FRP members}

In the last decades, composite materials technology has emerged to compete with conventional reinforcing materials for strengthening concrete structures, and it has been the subject of several studies. The new type of composite column consists of the in-place concrete core encased in a thin-walled PVC tube externally reinforced with FRP hoops, [20]. The spacing of the hoops depends on the required strength. For additional strength, steel bars can be used to reinforce the concrete core. The developing direction of modern structural engineering is large. Central to the analysis and design of CFPT-FRP composite members, is the identification of key parameters influencing its performance under environmental loads.

\section{Durability-plastic tube effect}

The durability of CFPT-FRP columns and concrete columns confined with FRP under harsh environmental conditions was examined [27]. The experimental results illustrated the effectiveness of the confinement system in improving strength and the energy absorption capacity of the axially tested concrete specimens. The advantages of CFPT-FRP were verified by an experimental investigation [28]. The main features of the new system included high bearing capacity and enhanced ductility. CFPT-FRP column is a composite system in which CFRP has reasonably excellent durability and an important practical value for engineering applications. Whereas PVC is an ideal material for the composite system, it is not only economical but also has excellent durability. The authors reported that CFPT-FRP provides a new form for the invention of a structural system, which has a bright future and development space. 
The influence of the chloride environment on the compression behavior of CFPT-FRP columns with carbon fibers was examined [29]. The tensile strength, elastic modulus, ultimate tensile strain, failure mode, bearing capacity, and the stress-strain relationship of CFPT-FRP specimens exposed to aggressive chloride environment remained relatively unchanged. The PVC tubes protect the core concrete and avoid the erosion of the chloride environment.

\section{Durability of composites}

In the past, considerable effort has gone into improving the mechanical performance of concrete members in aggressive marine environments using composite materials, where materials deterioration can considerably lessen the effects of confinement. Fiber-matrix interface was reported to be vulnerable to cracks after exposure to aggressive environments. Detrimental environmental agents have been reported to attack and damage the FRP composite surface texture, which may facilitate the penetration of aggressive ions found in water into the concrete core and steel reinforcement. Degradation of mechanical properties of FRP was reported previously and particularly for GFRP when subjected to aggressive environments. Exposure to freeze-thaw cycles reported leading to micro-cracks and de-lamination of the fiber-matrix interface [30]. Water affects the mechanical properties of in-plane wet lay-up composites. Thin-walled PVC tube filled with concrete can display considerable deformation under load and good durability performance [14]. The load capacity of PVC tubular-concrete sections might be improved using FRP composite materials as an external shell.

Water may also contribute to the damage of the polymer matrix, known as plasticization, [31]. Epoxy-layered silicate nanocomposites have the potential to lower the permeability of the matrix [32]. Two additive agents Silanes (organofunctional trialkoxysilanes) and organotitanates, have been used as a protection against diffusion into the matrix [33]. PVC presents chemical stability and protects the polymer resin from chemicals found in fresh concrete during the hydration of cement. The composite column possesses the high tensile strength capacity of CFRP and is a feasible proposal for the exceptional environment due to the good durability performance of PVC [7]. CFPTFRP durability is, for the most part, influenced by characteristics of FRP material and the polymeric PVC tube. Polymer composites are more resistant to degradation than many of their competitors [34]. The performance of polymer composite is a function of the service environment. The degree of interaction of the polymer with the service environment is one of the causes of its degradation. The long-term stability of the polymer will be dependent upon its durability in the environment into which it is placed and improvement in its barrier properties. Generally, the right application of the resin matrix should be sufficient to protect and shield the fibers from aggressive agents [35].

Durability tests [20] were conducted on hybrid concrete columns under different environmental conditions. Three fibers (glass, aramid, and carbon) which are consistently used in the construction industry were investigated. The specimens were confined with different FRP spacing and underwent 200 and 400 cycles of freeze /thaw or wet /dry. Axial stress-strain behavior was used to determine the influence of exposure conditions on the confined specimens. Durability tests illustrated that CFPT-FRP specimen with carbon fiber performed quite well under the severe exposure conditions. However, the CFPT-FRP with glass fiber and CFPT-FRP with aramid fibers showed reductions in both strength and ductility.

Whereas PVC is an ideal material for the composite system, it is not only economical but also has good durability and requires less construction time. The PVC tubes protect the concrete core and avoid the erosion of the chloride environment. The composite materials could play a vital role in improving the service life of infrastructure systems [11].

\section{Discussion}

\subsection{Durability results}

In a wide research program, PVC tubes confined laterally with a very modest volume of FRP were used in order to achieve more durable and economic structures [20]. Test variables included the type of fiber, the spacing between the FRP hoops, and the volume of fiber.The percentage of strength deterioration after zero cycles $f_{\text {cu( }(0)}$, $200 f_{\mathrm{cu}(200)}$ and $f_{\mathrm{cu}(400)} 400$ cycles of freeze/thaw or wet/dry is shown Table 1 . Also the percentage of improvement (positive sign) or reduction (minus sign) in the ultimate strength and strain of PVC-FRP columns after exposure to aggressive environments (freeze/thaw and wet/dry cycles) is also summarized in Table 1. Strength (fcu) and strain $\left(\varepsilon_{\mathrm{cu}}\right)$ values for minimum hoop spacing of $30 \mathrm{~mm}$ and maximum spacing of $78 \mathrm{~mm}$ for three types of fiber; carbon (C), aramid (A), and glass (G) were taken from the results reported [20]. Even after strength degradation, the strength ratio $\left(f_{\mathrm{f}} / f_{\mathrm{c}}\right)$ of all PVC-FRP specimens after 200 and 400 cycles (underlined bold values in Table 1 , $\underline{\mathbf{1 . 1 5}}, \underline{\mathbf{1 . 2}})$ for freeze and thaw cycles and $(\underline{\mathbf{2 . 0 5}}, \underline{\mathbf{1 . 7}})$ for wet/dry cycles were still higher than 33.00 for plain concrete control specimens; the underlined values show the maximum percentage of reduction in strength after $200(\underline{-8.9}),,(\underline{-7}$ ) and 400 ( $-\underline{16.2})(\underline{-15})$ cycles for both freeze/thaw and wet/dry tests. The deteriorations in strain 
of CFPT-FRP specimens are also shown in Table 1. As it can be seen from the above discussion the water resistant plastic tube plays vital role in the protection of CFPT-FRP columns since the FRP was partially wrapped and that meant the deleterious materials in the water can penetrate into the concrete core through the space between FRP hoops had the plastic tube was not used.

The strain ratio of confined to the unconfined specimen ( $\left.\varepsilon_{\mathrm{cuf}} / \varepsilon_{\mathrm{cuc}}\right)$ is shown in the last column of Table 1 for the three types of fibers. Underlined $(\underline{1.67,1.67})$ and $(\underline{0.7}, \underline{0.94})$ values are for maximum and minimum values of $\varepsilon_{\text {cuf }} \varepsilon_{\text {cuc }}$ after either freeze/thaw or wet/dry tests. The PVC tube was effective in protecting the concrete core and reducing the effect of exposure since the fiber was partially applied. However, the performance of the specimen was dependent on the type of fiber, hoop spacing (s), and type of exposure, with carbon fiber showing better resistance to severe environmental conditions. Critical reduction in ductility was observed for specimens with aramid fiber ( 0.7 , which is less than 1 for plain concrete) due to deterioration in the fiber-matrix interface, which reduces its ductility and protection capacity. Specimens confined with PVC-FRP with carbon fibers showed better mechanical performance compared with the other two types of fibers. CFRP Specimens with strip spacing of $78 \mathrm{~mm}$ showed similar performance to the other two types of fibers with $48 \mathrm{~mm}$ spacing. Hence, the choice is a trade-off between the increase in material cost and better mechanical performance.

Table 1. Durability test results of PVC-FRP confined concrete

\begin{tabular}{|c|c|c|c|c|c|c|c|c|c|}
\hline Ref. & $\begin{array}{l}\text { specim } \\
\text { en }\end{array}$ & $\begin{array}{l}f_{\mathrm{cu}(0)} \\
\mathrm{MPa}\end{array}$ & $\begin{array}{l}f_{\mathrm{cu}(200)} \\
(\%)\end{array}$ & $\begin{array}{l}f_{\mathrm{cu}(400)} \\
\mathrm{MPa}\end{array}$ & $\begin{array}{l}f_{\mathrm{f}} / \\
f_{\mathrm{c}}=\end{array}$ & $\begin{array}{l}\varepsilon_{\mathrm{cu}(0)} \\
(\%)\end{array}$ & $\begin{array}{l}\varepsilon_{\mathrm{cu}(200)} \\
(\%)\end{array}$ & $\begin{array}{l}\varepsilon_{\mathrm{cu}(400)} \\
(\%)\end{array}$ & $\begin{array}{l}\varepsilon_{\mathrm{cuf} /} \\
\varepsilon_{\mathrm{cuc}}=\end{array}$ \\
\hline \multirow{7}{*}{$\begin{array}{l}\text { Toutanji and } \\
\text { Saafi [20] } \\
\text { Freeze/thaw } \\
\text { cycles }\end{array}$} & plain & 33.00 & 3 & -3 & \multirow[t]{2}{*}{-} & 0.30 & 33 & -3.3 & \multirow{6}{*}{$\underline{0.94}$} \\
\hline & As30 & 72.63 & 1.3 & -2.7 & & 1.26 & 13.5 & -50.8 & \\
\hline & As78 & 44.12 & -2.5 & $\underline{-16.2}$ & \multirow[t]{2}{*}{$\underline{1.15}$} & 0.63 & $\underline{-55.6}$ & -14.3 & \\
\hline & Gs30 & 66.25 & -4 & $\overline{-10.6}$ & & 1.81 & -10.5 & -48.6 & \\
\hline & Gs78 & 43.50 & $\underline{-8.9}$ & -8 & \multirow[t]{4}{*}{$\underline{1.2}$} & 0.30 & 133 & -20 & \\
\hline & Cs30 & 96.00 & $\underline{9.4}$ & 2.6 & & 1.10 & -0.9 & -6 & \\
\hline & Cs78 & 60.00 & 9.2 & $\underline{3.5}$ & & 1.18 & -17.8 & $\underline{-57.6}$ & $\underline{1.67}$ \\
\hline \multirow{7}{*}{$\begin{array}{l}\text { Wet/dry } \\
\text { cycles }\end{array}$} & plain & 33.00 & 3 & 9 & & 0.30 & $\underline{23}$ & $\overline{16.7}$ & \\
\hline & As30 & 72.63 & $\underline{-7}$ & -11.5 & \multirow[t]{2}{*}{$\underline{2.05}$} & 1.26 & -8.7 & -52 & \\
\hline & As78 & 44.12 & -2 & -11.4 & & 0.63 & -28.6 & -66.7 & $\underline{0.7}$ \\
\hline & Gs30 & 66.25 & -3.2 & -15 & \multirow[t]{4}{*}{$\underline{1.7}$} & 1.81 & -13 & -72 & \multirow[t]{4}{*}{1.67} \\
\hline & Gs78 & 43.50 & -3 & -8 & & 0.30 & $\underline{23}$ & -26.7 & \\
\hline & Cs30 & 96.00 & $\underline{1.1}$ & 2 & & 1.10 & -12.7 & -32 & \\
\hline & Cs78 & 60.00 & -0.4 & 10.4 & & 1.18 & -3.3 & -69.5 & \\
\hline
\end{tabular}

Table 2. Experimental results for PVC-FRP confined concrete and the percentage of reduction in axial strength and strain due to increase in hoop spacing

\begin{tabular}{|c|c|c|c|c|c|c|c|c|}
\hline Ref. & specimen & $\begin{array}{l}h / D \\
\mathrm{~mm}\end{array}$ & $f_{\text {cu }} \mathrm{MPa}$ & $f_{\mathrm{cu}}-f_{\mathrm{co}} / f_{\mathrm{co}}$ & $\begin{array}{l}\% \\
\text { Redu. }\end{array}$ & $\varepsilon_{\mathrm{cu}}-\varepsilon_{\mathrm{co}} / \varepsilon_{\mathrm{co}}$ & $\begin{array}{l}\% \\
\text { Redu }\end{array}$ & $\varepsilon_{l}(\%)$ \\
\hline Toutanji and & As30 & 3 & 72.63 & 1.20 & & 5.3 & & 1.27 \\
\hline \multirow[t]{5}{*}{ Saafi [20] } & As78 & 3 & 44.12 & $\underline{0.30}$ & 75 & 1.6 & 70 & 0.90 \\
\hline & Gs30 & 3 & 66.25 & 1.00 & & $\underline{8.1}$ & & 1.70 \\
\hline & Gs78 & 3 & 43.50 & 0.32 & 68 & $\underline{0.5}$ & 94 & 0.50 \\
\hline & Cs30 & 3 & 96.00 & $\underline{1.90}$ & & 4.5 & & 1.10 \\
\hline & Cs78 & 3 & 60.00 & 0.82 & 57 & 5.1 & +13 & 1.18 \\
\hline $\mathrm{Yu}[40]$ & $\mathrm{SF} \rho-0.34$ & 2.5 & & 1.03 & & $7.8^{*}$ & & 1.22 \\
\hline$*=\varepsilon_{\mathrm{cu}} / \varepsilon_{\mathrm{co}} \mathrm{D}$ & $\mathrm{SF} \rho-0.21$ & 2.5 & & 0.42 & 59 & $6.3^{*}$ & 19 & 1.26 \\
\hline \multirow[t]{4}{*}{ Niu et al. [39] } & E20Cs20 & & & 0.7 & & & & \\
\hline & E20Cs60 & & & 0.15 & 79 & & & \\
\hline & E40Cs20 & & & 0.47 & & & & \\
\hline & E40Cs60 & & & 0.07 & 85 & & & \\
\hline \multirow{4}{*}{$\begin{array}{l}\text { Jiang et al. } \\
\text { [25] }\end{array}$} & C30N2M3 & 3 & 1669.9 & & & & & \\
\hline & C30N2M5 & 5 & 1540.7 & & 7.7 & & & \\
\hline & C30N2M7 & 7 & 1413.9 & & 15.3 & & & \\
\hline & C30N2M9 & 9 & 1016.5 & & 39.1 & & & \\
\hline
\end{tabular}

E=steel reinforced 


\subsection{Ultimate strength}

Test results of ultimate strength $f_{c u}$ and strain $\varepsilon_{c u}$ for CFPT-FRP columns from previous works are shown in Table 2. The ultimate strength and strain decreased with an increase in hoop spacing, and the percentage of reduction is calculated and is shown in Table 2. For example increasing the hoop spacing from 38mmAs30 to $78 \mathrm{~mm}$ As78 resulted in $75 \%$ reduction in strength of PVC-FRP column, whereas the same reduction was $70 \%$ for strain. One specimen experienced increase in strain (13\%) as the hoop spacing was increased from Cs30 to Cs78.

Generally, the ultimate strength of the specimen was improved by a minimum of $32 \%(43.5-33 / 33=0.32$ ) for specimen with Gs78 and a maximum of 190\% (96-33/33=1.9) for specimen with Cs30 when the external PVCFRP shell used to confine concrete. The improvement in axial strain ratio ranged from zero for specimen with Gs78 to five folds for specimen with Gs30. For CFPT-FRP steel-reinforced columns, the percentage of reduction was higher. Some studies have reported that CFPT-FRP columns had increased the ultimate strength and strain of concrete by 3 [37] and 15 [25] times, respectively. The bearing capacity of the PVC-FRP column is the sum of the strength capacity of two thin-walled sections (PVC tube and FRP-matrix) and concrete core. However, the confining pressure due to the PVC tube was neglected by most models because of its low stiffness. The strength of the PVC tube in the longitudinal direction is the strength of the CFPT-FRP composite member.Several models have been developed for predicting the strength of concrete filled plastic tube externally strengthened with fibers. Table 3 shows the predictions of axial compression strength of PVC-FRP confined concrete according to each reference with internal steel reinforcement (underlined values) and without.

Table 3. Comparison between experimental and predicted axial compression results of PVC-FRP confined concrete according to each reference

\begin{tabular}{|c|c|c|c|c|c|c|c|}
\hline Reference & Specimen & $\begin{array}{l}f_{\mathrm{cu} \text {,Ex }} \\
\mathrm{MPa} \\
\end{array}$ & $\begin{array}{l}f_{\mathrm{cu}, \mathrm{Pr}} \\
\mathrm{MPa} \\
\end{array}$ & $\begin{array}{l}f_{\mathrm{cu}, \mathrm{Pr} /} \\
f_{\mathrm{cu}, \mathrm{Ex}}\end{array}$ & $\varepsilon_{\mathrm{cu}, \mathrm{Ex}}$ & $\varepsilon_{\mathrm{cu}, \mathrm{Pr}}$ & $\begin{array}{l}\varepsilon_{\mathrm{cu}, P r} / \\
\varepsilon_{\mathrm{cu}, E x} \\
\end{array}$ \\
\hline Toutanji and & As30 & 72.63 & 75.71 & 1.04 & 1.26 & 1.36 & 1.08 \\
\hline \multirow[t]{5}{*}{ Saafi [20] } & As78 & 44.12 & 40.91 & 0.93 & 0.63 & 0.64 & 1.02 \\
\hline & Gs30 & 66.25 & 63.67 & 0.96 & 1.81 & 1.93 & 1.07 \\
\hline & Gs78 & 43.50 & - & & 0.3 & - & \\
\hline & Cs30 & 96.00 & 100.9 & 1.05 & 1.1 & 1.04 & 0.95 \\
\hline & Cs78 & 60.00 & 59.31 & 0.99 & 1.21 & 1.14 & 0.94 \\
\hline Yu and Niu [23] & A-Cs20-1 & 1812.4 & 1872.24 & 1.03 & 0.0162 & 0.0175 & 1.08 \\
\hline \multirow[t]{3}{*}{ JPS* } & A-Cs20-2 & 1756.8 & 1872.24 & 1.07 & 0.0182 & 0.0175 & 0.96 \\
\hline & A-Cs60-1 & 1260.11 & 1220.1 & 0.97 & 0.0132 & 0.0132 & 1.00 \\
\hline & A-Cs60-2 & 1327.2 & 1220 & 0.92 & 0.0126 & 0.0132 & 1.05 \\
\hline Yu and Niu & A-Cs20 & 1784 & 1752.6 & 0.98 & 0.0162 & - & - \\
\hline \multirow[t]{3}{*}{ [41] JBS } & A-Cs60 & 1294.2 & 1162.9 & 0.9 & 0.0144 & - & - \\
\hline & AR-Cs20 & 2043 & 2173.2 & 1.06 & 0.0199 & - & - \\
\hline & $\underline{\mathrm{AR}-\mathrm{Cs} 60}$ & $\overline{1600}$ & 1442.0 & 0.9 & 0.0146 & - & - \\
\hline \multirow{4}{*}{$\begin{array}{l}\text { Fakharifar } \\
\text { and Chen [26] }\end{array}$} & $1 \mathrm{C} \# 1$ & $\overline{66.5}$ & - & - & 0.90 & - & - \\
\hline & 3С\#1 & 86.0 & - & - & 1.38 & - & - \\
\hline & $1 \mathrm{G} \# 1$ & 59.0 & - & - & 1.42 & - & - \\
\hline & 1G\#foam & 47.9 & & & 0.73 & - & - \\
\hline Yu et al. & A-Cs20 & 56.8 & 52.1 & 0.92 & 0.0172 & 0.0171 & 1 \\
\hline [42] & A-Cs60 & 40.1 & 37.5 & 0.94 & 0.0192 & 0.0118 & 0.62 \\
\hline \multirow{4}{*}{ Jiang et al.[25] } & ZD-1 & 39.25 & 38.77 & 0.99 & & & \\
\hline & ZD-2 & 40.55 & 41.97 & 1.04 & & & \\
\hline & ZD-3 & 42.85 & 45.17 & 1.05 & & & \\
\hline & ZD-4 & 47.75 & 48.37 & 1.01 & & & \\
\hline \multirow[t]{8}{*}{ Yu et al.[43] } & JC20n11 & 85.77 & 82.27 & 0.96 & 37.36 & 29.78 & 0.8 \\
\hline & $\overline{\text { JC20n21 }}$ & 133.5 & 120.3 & 0.9 & 4 & 4.78 & 1.2 \\
\hline & $\overline{\text { JC60n11 }}$ & 83.8 & 65.92 & 0.79 & 31.9 & 31.23 & 0.98 \\
\hline & $\overline{\text { JC60n21 }}$ & 104.8 & 93.96 & 0.9 & 19.4 & 17.04 & 0.88 \\
\hline & $\overline{\mathrm{JC} 20 \mathrm{n} 12}$ & 56.93 & 57.71 & 1.01 & 44.76 & 44.7 & 1 \\
\hline & JC20n22 & 82.77 & 95.75 & 1.16 & 19.93 & 24.52 & 1.23 \\
\hline & JC60n12 & 51.42 & 51.35 & 1 & 54.9 & 52.15 & 0.95 \\
\hline & $\overline{\mathrm{JC60n} 22}$ & 67.41 & 69.4 & 1.03 & 39.79 & 31.97 & 0.8 \\
\hline \multirow[t]{4}{*}{ Yu et al. [44] } & $\overline{\text { E20Cs20 }}$ & 1833 & 1811.4 & 0.99 & & & \\
\hline & E20Cs60 & 1314.3 & 1398.7 & 1.06 & & & \\
\hline & E40Cs20 & 1372.3 & 1342.2 & 0.98 & & & \\
\hline & E40Cs60 & 1092.9 & 1042.5 & 0.95 & & & \\
\hline
\end{tabular}




\subsection{Flexural members}

The absence of yield and plasticity in FRP materials used in CFPT-FRP members subjected to flexural loads can be partially compensated by the flexibility of the PVC tube. The polymeric plastic tube can play a role in the final failure mode of the member due to its excessive deformability, which is a warning sign of the impending failure [9]. The ability of the composite member to absorb energy when loaded in the lateral direction is of considerable importance when considering its short and long-term mechanical behavior. To systematically assess the behavior of CFPT-FRP specimens, the flexura1 behavior of five CFPT-FRP circular tubular members were evaluated [36]. One specimen was confined with carbon fiber and the remaining four with basalt fiber, which is much cheaper than carbon fiber. Additionally, one specimen was confined by PVC only. The tested specimens, $200 \mathrm{~mm}$ in diameter and $1500 \mathrm{~mm}$ in length, were reinforced with six longitudinal steel bars and 6mm stirrups at $120 \mathrm{mmc} / \mathrm{c}$. Design parameters such as failure modes, ultimate bending capacity, and stress-strain relations were considered. Using CFRP and BFRP, the bending capacity and ductility were enhanced. The reinforcement effect in CFRP (237.35\%) was better than that in BFRP (68.67- 195.18\%). A formula was proposed for predicting the theoretical bending capacity.

In a similar study, the flexural behaviors of CFPT-FRP specimens were examined [38]. The main parameters of the test included the types and layers of FRP. A procedure code was developed for the finite element analysis. Based on the experimental results, it was verified that the simulation results obtained from the proposed model were in good agreement with the obtained experimental results. However, the confining effect in CFRP was better than that in BFRP. In their latest work, Fakharifar and Chen [39] have elaborated on a new ductile design concept for the new hybrid column, introduced in an earlier paper by the authors. Results illustrated that the 152 by $1524 \mathrm{~mm}$ flexural beams tested under four-point loading had significantly enhanced ductility due to the presence of the compressible Foam, which acts as an energy dissipation medium. The interface property between the FRP and PVC was proved to be critical in the composite column design. Table 4 summarizes the flexural test results of CFPT-FRP confined concrete from previous research. Peak values for strength $\left(P_{\text {peak }}\right)$, moment $\left(M_{\text {peak }}\right)$, and displacement $\left(\Delta_{\text {peak }}\right)$ and corresponding ultimate $\left(P_{u l t}\right)$, moment $\left(M_{u l t}\right)$, and displacement values $\left(\Delta_{u l t}\right)$ are shown for some of the measured properties to be dependent on fiber type, volume, and spacing.

Table 4. Flexural test results of PVC-FRP confined concrete

\begin{tabular}{|c|c|c|c|c|c|c|c|}
\hline Reference & specimen & $\begin{array}{c}P_{\text {peak }} \\
\mathrm{KN}\end{array}$ & $M_{\text {peak }} \mathrm{KNm}$ & $\begin{array}{l}\Delta_{\text {peak }} \\
\mathrm{mm}\end{array}$ & $\begin{array}{l}P_{\text {ult }} \\
\mathrm{KN}\end{array}$ & $\begin{array}{l}\Delta_{\text {ult }} \\
\mathrm{mm}\end{array}$ & $\begin{array}{l}P_{\mathrm{uEx}} / \\
P_{\mathrm{uPr}}\end{array}$ \\
\hline \multirow[t]{3}{*}{ Fak [38] } & CCFPT1 & 35.9 & 7.3 & 14.8 & & & \\
\hline & CFoam2 & 78.6 & 16 & 79.3 & 62.9 & 111.7 & \\
\hline & ССFРТЗ & 169.6 & 34.5 & 30.6 & & & \\
\hline \multirow[t]{4}{*}{ Niu et al. [39] } & E20Cs20 & & 58.36 & 4.52 & & & \\
\hline & E20Cs60 & & 51.36 & 5.25 & & & \\
\hline & E4Cs20 & & 84.62 & 6.00 & & & \\
\hline & E4Cs60 & & 59.81 & 5.72 & & & \\
\hline \multirow[t]{4}{*}{ Yu et al. [44] } & E20Cs20 & & 47.4 & & & & \\
\hline & E20Cs60 & & 33.53 & & & & \\
\hline & E40Cs20 & & 62.3 & & & & \\
\hline & E40Cs60 & & 44.85 & & & & \\
\hline Wu et al. & Z2H0-B & & 36.75 & & 210 & 38.44 & 1.03 \\
\hline \multirow[t]{4}{*}{ [43] } & Z3H0-B & & 28 & & 160 & 18.52 & . \\
\hline & Z2H2-B & & 45.5 & & 260 & 40.55 & 1.05 \\
\hline & Z3H3-B & & 49 & & 280 & 43.47 & 1.00 \\
\hline & Z2H2-C & & 56 & & 320 & 62.68 & 0.99 \\
\hline \multirow{5}{*}{ Ma et al.[37] } & Z2H0-B & & & & & & $1.04^{1}$ \\
\hline & Z3H0-B & & & & & & - \\
\hline & Z2H2-B & & & & & & $1.02^{1}$ \\
\hline & Z3H3-B & & & & & & $0.99^{1}$ \\
\hline & Z2H2-C & & & & & & $0.92^{1}$ \\
\hline
\end{tabular}

${ }^{1}$ means $M_{\mathrm{u}} / M_{\mathrm{c}}$ ratio

\section{Conclusions}

The durability of CFPT externally strengthened with fiber-reinforced polymers reviewed in the current study. The following conclusions are drawn:

1)There is a general consensus among the researches that PVC tubular has the potential to encase concrete efficiently and enhance both the load capacity and ductility and improve energy absorbing capacity of resulting 
PVC-concrete composite member.

2) One shortcoming of the PVC tube is its low stiffness. The current review shows that the characteristic of the PVC tube is greatly enhanced when it is externally wrapped with FRP straps.

3) The lack of ductility in FRP composite materials can be compensated by ductile polymer PVC tubes, which exhibit considerable elongation at breaking.

4) The new composite system for construction combines the stiffness of FRP and the ductility of PVC tubular. CFPT-FRP columns show considerable capacity to deform plastically and dissipate internal strain energy under the applied loads.

5)The current study established that the use of PVC-FRP enables the structure to carry more load than it was designed for because the contribution of PVC tube, especially its load-carrying capacity in the axial direction, is usually not counted for by most of the strength models. This would be beneficial when the capacity of the column needs to be increased due to increased vertical loads.

6) Future research is much needed on the PVC tube material technology to extend their application range to include noncircular cross-sectional members.

An awareness of environmental influence and sensitivity has been one of the focuses of the current study with emphasis on the practical application of technical knowledge in civil engineering applications and the extensive use of composite materials for the development of an understanding of engineering behavior of such systems. As experience and comfort with the material grow, the requirements on the technical content will get higher and will be helpful in advancing the state of practice.

\section{References}

[1] Lee SWR, Li Z, Tang JM, Lee S, Tong P. Development of composite grid tubes for the reinforcement of concrete columns. ICCM12, Conference Paris. 1999. p. 549.

[2] Cusson D, Paultre P. High strength concrete columns confined by rectangular ties. ASCE Journal of Structural Engineering. 1994; 120(3): 783-804.

[3] Ahmad SH, Shah SP. Stress-strain curves of concrete confined by spiral reinforcement. ACI Structural Journal. 1982; 79(6), 484-490.

[4] Susantha KAS, Ge H, Usami T. Uniaxial stress-strain relationship of concrete confined by various shaped steel tubes. Engineering Structures. 2001; 23(10): 1331-1347.

[5] Mirmiran A, Shahawy M. Behavior of concrete columns confined by fiber composites. ASCE Journal of Structural Engineering. 1997; 123(5): 583-590.

[6] Saadoon AS. Experimental and theoretical investigation of PVC-concrete composite columns. [Doctoral dissertation]. University of Basrah, Iraq. 2010

[7] Abdulla NA. Concrete filled thermoplastic tube under compression. In: Proceedings of the 1st International Engineering Conference on Developments in Civil and Computer Engineering Applications. University of Ishik, Erbil, Iraq. 2014. p.60-70.

[8] Oyawa WO, Githimba NK, Mang'urio GN. Structural response of composite concrete filled plastic tubes in compression. Steel and Composite Structures. 2016;21(3):589-604.

[9] Abdulla NA. Concrete filled PVC tube: A review. Construction and Building Materials. 2017;156:321-329.

[10] Kurtoglu AE, Hussein AK, Gulsan ME, Altan MF, Cevik A. Mechanical investigation and durability of HDPE-confined SCC columns exposed to severe environment. KSCE Journal of Civil Engineering. 2018; 22(12):5046-5057

[11] Abdulla NA. Influence of plastic pour-in form on mechanical behavior of concrete. Structures. 2019; 19 : $193-$ 202

[12] Raheemah MA, Resan SF. Experimental investigation of concrete columns enhanced by PVC tubes. IOP Conference. Ser.: Material Science Engineering. 2019;584:012047

[13] Abdulla NA. The behavior of concrete-filled plastic tube specimens under axial load. Jordan Journal of Civil Engineering. 2020; 14(1):69-81.

[14] Abdulla NA. Concrete encased with engineering plastics. Journal of Civil Engineering and Construction. 2020; 9(1):31-41.

[15] Abdulla NA. Mechanical behavior of slender composite columns under axial compression load. KSCE Journal of Civil Engineering. 2020; 24(1):208-218

[16] Bandyopadhyay A, Maurya KK, Samanta AK. Investigation on UPVC confined RC columns with recycled aggregate concrete using C\&D waste. Structures. 2020; 23: 279-288.

[17] Abdulla NA. Concrete with an outer plastic protective shell. SN Applied Science. 2020;2(6):1-10.

[18] Abdulla NA. Using the artificial neural network to predict the axial strength and strain of concrete-filled plastic tube. Journal of Soft Computing in Civil Engineering. 2020. DOI:10.22115/scce.2020.225161.1198.

[19] Abdulla N A. Axial strength of short concrete-filled plastic tube. Structures. 2020; 27: 1786-1800. 
[20] Toutanji H, Saafi M. Durability studies on concrete columns encased in PVC-FRP composite tubes. Composite Structures. 2001; 54(1): 27-35.

[21] Li YL, Zhao XL, Singh RKR, Al-Saadi S. Experimental study on seawater and sea sand concrete filled GFRP and stainless steel tubular stub columns. Thin-Walled Structures. 2016; 106: 390-406.

[22] Akram S, Mahmood AA, Al-badrany R. The numerical simulation of axial crumpling in grooved circular PVC tubes under static compression. Journal of Engineering Science and Technology. 2015; 10 (10): 1350 1360.

[23] Yu F, Niu D. Stress-strain model of PVC-FRP confined concrete column subjected to axial compression. International Journal of Physics Science. 2010; 5(15): 2304-2309.

[24] Fakharifar M, Chen G, Lin Z, Woolsey ZT. Behavior and strength of passively confined concrete filled tubes. Tenth U.S. National Conference on Earthquake Engineering. Frontiers of Earthquake Engineering, Alaska. 2014; $440-446$.

[25] Jiang S, Wu Z, Wu Z, Yu B. Experimental study on reinforced concrete columns confined by FRP-PVC tubes under reversed loading. Journal of Building Structures. 2014; 35(2): 111-118. (In Chinese)

[26] Fakharifar M, Chen G. Compressive behavior of FRP-confined concrete-filled PVC tubular columns. Composite Structures. 2016; 141: 91-109.

[27] Toutanji H, Zhao L, Isaacs G. Durability studies on concrete columns confined with advanced fiber composites. International Journal of Materials Product Technology. 2007; 28(1-2): 8-28.

[28] Yu F, Wu P. Study of behavior of new composite structural column. Industrial Building. 2009; 39(2), 97-99. (In Chinese)

[29] Yu F, Niu D. Experimental study on axial performance of PVC-CFRP confined concrete column under chloride environment. J. Building Structures. 2014; 35:159-164. (In Chinese)

[30] Micelli F, Myers JJ. Durability of FRP-confined concrete. Proc. ICE Constr. Mater. 2008; 161(4): 173-185.

[31] Sciolti MS, Frigione M, Aiello MA. Wet lay-up manufactured FRPs for concrete and masonry repair: Influence of water on the properties of composites and on their epoxy components. Journal Composites for Construction. 2010;14(6):823-833.

[32] Hackman I, Hollaway LC. Epoxy-layered silicate nanocomposites in civil engineering. Composite Part A. 2006; 37(8): 1161-1170.

[33] Van OW, Zhu D, Stacy M, Seth A, Mugada T, Gandhi J. Corrosion protection properties of organofunctional silanes - an overview. Tsinghua Science Technology. 2005;10(6): 639-64.

[34] Hollaway LC. A review of the present and future utilization of FRP composites in the civil infrastructure with reference to their important in-service properties. Construction and Building Materials. 2010; 24: 2419-2445

[35] Micelli F, Nanni A. Durability of FRP rods for concrete structures. Construction and Building Materials. 2004; 18(7): 491-503.

[36] Guo YC, Huang PY, Yang Y. Experimental studies on axially loaded concrete columns confined by different materials. Key. Eng. Mater. 2008; 400:513-518.

[37] Ma S, Lin Q, Jiang S. Experimental study on flexural behavior of circular concrete-filled FRP-PVC tubular members. Journal of Shenyang Jianzhu University. (Natural Science). 2012; 28 (6): 988-996.

[38] Wu W, Lin Q, Jiang S. Study on the behavior of concrete-filled FRP-PVC tubular flexural members. Engineering Mechanics. 2015; 32 (6):104-110. (In Chinese)

[39] Fakharifar M, Chen G. FRP-confined concrete filled PVC tubes: A new design concept for ductile column construction in seismic regions. Construction and Building Materials. 2017; 30: 1-10.

[40] Niu D, Yu F, Wang Z. Eccentric compression performance of PVC-CFRP confined reinforced steel tube concrete column. Journal of Acta Material Composite Sinica, 2017; 34(10): 2356-2366. (In Chinese)

[41] Yu F, Niu D. Experimental study on PVC-FRP confined short column under axial compression. Journal Building Structure. 2013; 34(6): 129-136. (In Chinese)

[42] Yu F, Cheng A, Xu G, Li D. Nonlinear finite element analysis of PVC-FRP confined concrete short column under axial compression. Industrial Construction. 2015; 45(4): 77-82. (In Chinese)

[43] Yu F, Xu G, Cheng A. Study on restoring force model of PVC-CFRP tube confined reinforced concrete column. J. Build. Struct. 2015; 36(9): 66-72. (In Chinese)

[44] Yu F, Li D, Niu D, Xu G, Cheng A, Xu L. Analysis on bearing capacity of PVC-FRP confined reinforced concrete columns under eccentric compression tubes. J. Xi'an Uni. Arch. Technol. (Natural Science Edition). 2014; 46(05). (In Chinese)

(C) 2020 by the author(s). This work is licensed under a Creative Commons Attribution 4.0 International License (http://creativecommons.org/licenses/by/4.0/). Authors retain copyright of their work, with first publication rights granted to Tech Reviews Ltd. 